\title{
Teatro e intermedialidade
}

\section{Fernando Matos Oliveira}

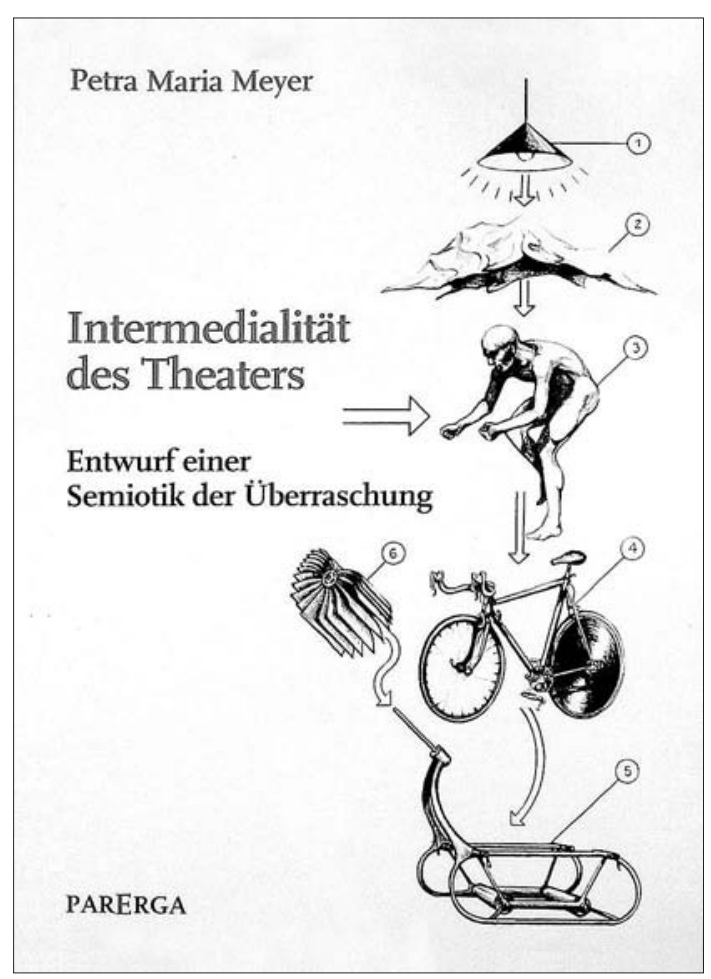

Passada a voragem semiológica dos anos setenta e oitenta, devidamente amplificada pelo trajecto emancipatório da própria encenação teatral, o estudo sistemático dos fenómenos de significação em contexto artístico tem passado por um período algo intermitente. A publicação de livros como o de Petra Maria Meyer, intitulado A intermedialidade do teatro. Para uma semiótica da surpresa, (Intermedialität des Theaters. Entwurf einer Semiotik der Überraschung, Düsseldorf, Parerga Verlag, 2001), recorda-nos a sintonia crítica que desde cedo se verificou entre o teatro e os procedimentos analíticos desta tradição teórica. Um dos contributos mais enfáticos do livro de Petra Meyer consiste precisamente no modo como confronta a resistência da teatralidade contemporânea ao programa de leitura tradicionalmente proposto pela semiótica,

1 A L'Arche publicou, em 2002, uma tradução francesa sob o titulo Le Théâtre postdramatique.

2 "Experience is our only teacher. But precisely how does this action of experience take place? It takes place by a series of surprises". especialmente no que diz respeito à necessidade prévia de conceptualizar unidades sígnicas ou segmentos cénicos, devidamente identificados e estabilizados. Neste sentido, 0 volume prossegue pelos seus próprios meios a análise do espectáculo contemporâneo que a crítica teatral germânica vem desenvolvendo na última década, período que teve no ensaio de Hans-Thies Lehmann intitulado Teatro pós-dramático (Postdramatisches Theater, 1999) uma das suas realizações mais proficientes.'

Petra Meyer começa por assumir a teoria teatral sobretudo como uma teoria medial, um discurso que julga capaz de acrescentar a legibilidade dos múltiplos suportes mediáticos que constituem o universo teatral contemporâneo. A tarefa a que se propõe é dupla: por um lado, defende a constituição medial de uma teoria do teatro; por outro, busca um modelo analítico que possa responder às transformações, cruzamentos e sobreposições intermediais que caracterizam o teatro de hoje. É neste plano que a proposta de uma "semiótica da surpresa" visa acolher a natureza contingente das linguagens cénicas actuais, marcadas por estratégias de reciclagem intermedial, recorrendo com frequência às técnicas e aos arquivos simbólicos do cinema, da pintura, da música etc.. 0 termo "surpresa" emana dos escritos de Charles Sanders Peirce, citado em epígrafe: "A experiência é o nosso único magistério. Mas exactamente como é que ela acontece? Acontece através de uma série de surpresas".2

Para que uma "semiótica da surpresa" não acabe num ecumenismo teorético sem consequências, Petra Meyer recorre sistematicamente ao estudo de casos concretos. A evidência empírica recolhida em cada um destes casos pretende actuar como instância de controlo e de aferição conceptual. Os autores a que confere maior destaque incluem coreógrafos, cenógrafos, dramaturgos, encenadores, agrupamentos de teatro e músicos. Refiram-se, em primeira linha, os casos de John Cage, Merce Cunningham, Jasper Johns, Erich Wonder, Heiner Goebbels, The Wooster Group, Hansgünther Heyme, Robert Wilson, Richard Foreman, John King e Prince. 0 próprio ensaio adopta uma estruturação para-teatral, declaradamente "encenada como uma cenografia-escrita". Esta composição estrutural inclui um prelúdio, cenas, onze secções designadas "Actos de pensamento" e ainda cinco "Knee-plays", um conceito directamente pilhado da obra de Robert Wilson. 0 discurso procura deste modo replicar uma certa intimidade conceptual relativamente ao objecto de análise, sem com isso hipotecar o seu próprio espaço crítico.

0 ensaio avança desde o início com a articulação entre o quadro semiológico e o discurso pós-estruturalista de autores como Barthes, Deleuze, Foucault, ou Derrida. 0 modo como a configuração plurimedial dos actuais processos espectaculares desafia abordagens de teor estritamente "lógico-analítico" justificaria esta opção. A incorporação do dicionário pós-estruturalista, a que se junta o pensamento estético frankfurtiano, propõe-se capacitar o discurso crítico para a leitura dos diversos registos que caracterizam a cena contemporânea. Ao longo dos capítulos da obra, a "semiótica da surpresa" devém progressivamente um espaço contíguo à différence pós-estruturalista, forjando uma compatibilidade baseada na latitude de conceitos como texto, escrita ou rizoma. Neste contexto, a reflexão estética de Theodor Adorno impõe-se pelo tom premonitório. A sua referência 
à fusão entre as artes ou ao entrelaçar (Verfransung) das várias expressões artísticas é uma análise válida da situação presente, momento em que a pressão hegemónica da modernidade tende a sobrepor-se às diferenças modais e funcionais. À medida que cada expressão artística se emancipa dessa sua especificidade modal, a aproximação mútua torna-se mais provável. Emergindo como herança vanguardista, a fusão (adorniana) entre as artes adquire na narrativa de Petra Meyer um sentido renovado na era electrónica e digital, período que verdadeiramente epitomiza o diálogo intermedial e a influência das novas tecnologias. A era cibernética sustentaria uma espécie de semiose interminável, um espaço no qual a materialidade exponente pode atenuar a própria fronteira entre o estético e o científico.

A vinculação intermedial do teatro, diga-se, vinha sendo confirmada no plano da recepção e da análise, pois os estudos teatrais recorrem frequentemente ao apoio de outros meios, de forma a compensar a natureza evanescente do acontecimento espectacular. Como o palco não produz artefactos no sentido clássico do termo, o próprio processo de interpretação tende a socorrer-se de diversos complementos textuais e visuais. De certo modo, cada exercício de memória implica uma negociação intermedial, de acordo com o contributo testemunhal de cada um dos meios em causa. Esta realidade é hoje mais premente, pois além das representações gráficas tradicionais - como a gravura e o desenho -, a fotografia e o vídeo surgiram como dois meios particularmente poderosos. 0 aparato técnico da pós-modernidade marca as diversas actividades estéticas e simbólicas, actuando como extensão sensorial capaz de condicionar os hábitos perceptivos forjados ao longo de séculos. Não por acaso o livro abre com um prelúdio metodológico em torno de uma fotografia com o espaço teatral de Knossos, antecedendo um momento crítico constituído por uma sequência de cinco leituras, centrada nas questões da representação e da percepção. A foto, tirada pela autora em 1994, surge nestas páginas como pretexto para uma reflexão preliminar em torno da densidade semiótica inerente à representação fotográfica. Cada exercício de leitura adianta o jogo entre o observador e o observado, tornando por vezes indistinta a fronteira entre o interior e o exterior da moldura fotográfica.

Percebemos que a imagem reproduzida no livro, antes mesmo de nos confrontar, acumula duas realidades em simultâneo: (a) o olhar contingente e pessoal da fotógrafa e (b) os contornos referenciais de um espaço teatral antigo que a passagem dos anos foi tornando indiferenciado para o turista acidental. Em 1994, a distinção entre a paisagem e o espaço cultural de Knossos parece pedir já um esclarecimento suplementar, presente sob a forma de um cartaz informativo dirigido aos visitantes. A legenda orienta assim a percepção mimética da imagem, actuando como uma especificação complementar. Entre a imagem, o texto do cartaz e o olhar do espectador estabelece-se um diálogo que é em grande parte um diálogo motivado pelo tipo de interferências e de transposições mediais que no livro se projectam em inúmeros criadores. Na verdade, esta dramatização do olhar em torno de Knossos antecipa e metaforiza um movimento correspondente no teatro contemporâneo, onde a presença crescente de meios

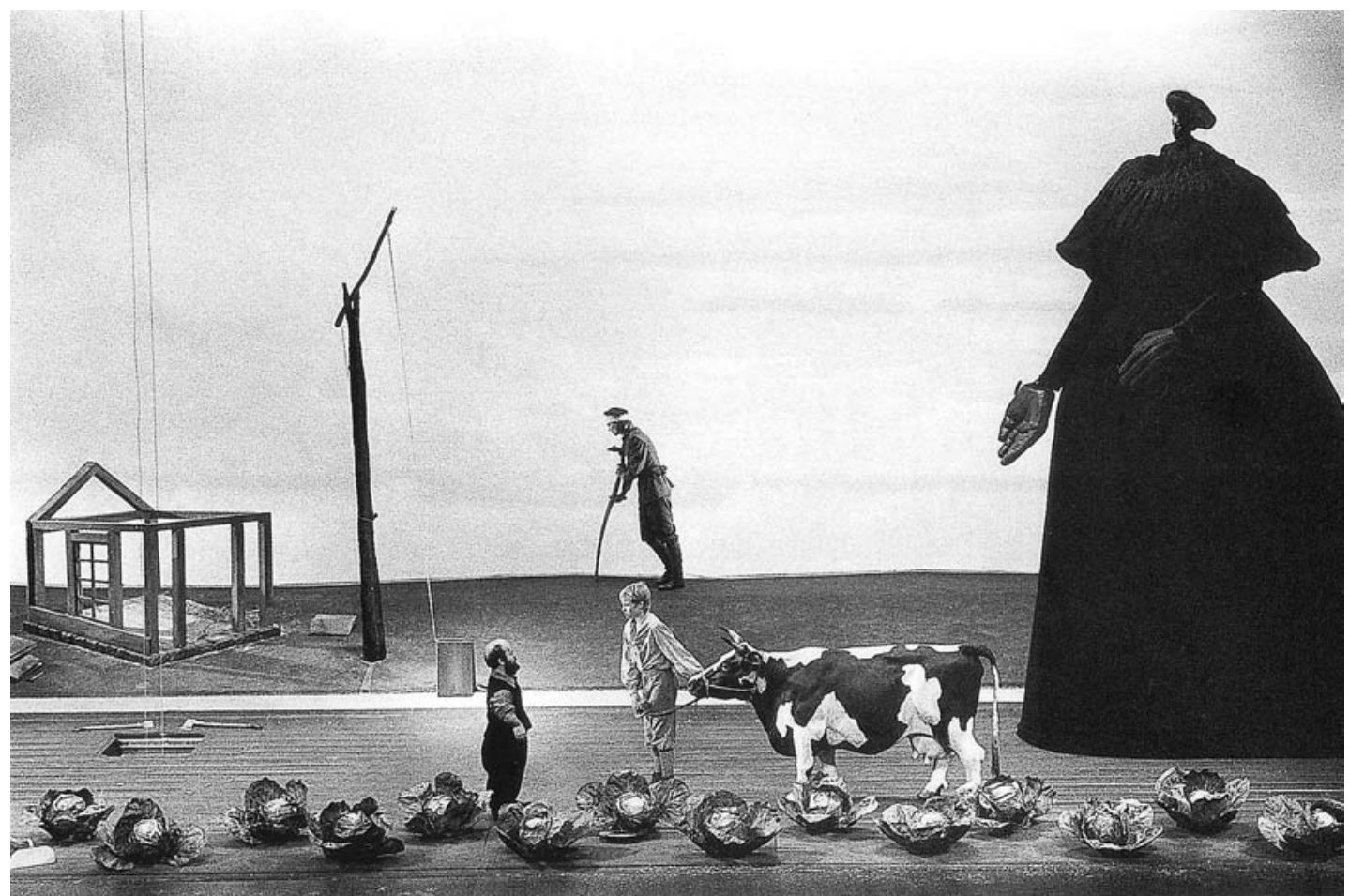


audiovisuais leva mais longe do que nunca a implicação entre o virtual e o real.

A foto de abertura assinala o papel das tecnologias modernas na preservação, selecção e processamento da memória, incluindo as experiências mais singulares. Tratase de um programa a que Friedrich Kittler atribuiu um sentido histórico-cultural determinante, como é sabido. No caso da foto, o facto de a duplicação mimética produzida pela câmara se assemelhar ao efeito tautológico do teatro entendido como "imitação da vida", aproxima ainda ambos os meios do ritual mortuário referido por Barthes. 0 regresso ao passado resulta da retórica temporal activada pela representação fotográfica, à qual o teatro vai frequentemente pedir um testemunho que julga suficiente para controlar o seu ímpeto transitório.

0 grosso do ensaio de Petra Meyer consiste numa espécie de mapeamento crítico das relações e cruzamentos entre as artes em contexto espectacular. A escrita adopta ela própria uma configuração algo rizomática, tendo em conta a fusão constante entre criadores e críticos dos últimos 30 anos. 0 conceito de intermedialidade não pretende ser uma revisitação holística da obra de arte total delineada nos escritos operáticos de Richard Wagner. ${ }^{3}$ Pelo contrário, o estudo contempla a análise do que é irredutivel em cada meio expressivo, inclusive nos chamados espectáculos multimédia. Na passagem para o século XXI, a organicidade da Gesamtkunswerk wagneriana aparecenos boicotada por aquilo a que F. Kittler, no seu ensaio de referência designava como a intradutibilidade fundamental de cada meio, expresso na fórmula "um meio é um meio é um meio" (cf. Aufschreibsysteme 1800/1900, München, Wilhelm Fink Verlag, 1985). Em rigor, o ordenamento da experiência que define a materialidade especifica de um meio sugere que a teorização intermedial deve assumir a arbitrariedade inerente a todo o fenómeno de transposição. Com efeito, o catálogo conceptual de Petra Meyer sustenta isto mesmo, ao confrontar o teatro e o espectáculo com um dicionário que inclui, entre outros, os seguintes termos: metateatralidade, repetição, tradução, transformação, evento, espontaneidade, acaso, singularidade, musicalização, experimentação, translocalização, cruzamento, intertextualidade, durée ou mediação.

"Semiótica da surpresa" é o nome colectivo que no final do ensaio procura designar a complexidade sígnica que define o quadro conceptual acima delineado. 0 desafio colocado pela actualidade espectacular a qualquer intento semiótico passa precisamente pela pujança criativa desta significação mutante. Petra Meyer procura resolver esta dificuldade insistindo na centralidade do ritmo no teatro contemporâneo. A dominância teorética do ritmo é também uma prova do triunfo da encenação, num teatro progressivamente dominado pelo princípio da performatividade. 0 ritmo permite à autora apreender criticamente o catálogo das mutações e transgressões sígnicas. Se a conexão entre o ritmo e a encenação é legítima, a multiplicidade de linguagens, de memórias e de códigos mobilizados pelo palco actual sintoniza plenamente com o carácter sensorial e espontâneo associado à experiência rítmica. Aqui radica, em última análise, a proposta de uma "semiótica da surpresa". Divergindo da semiótica tradicional, a atenção centra-se naquilo que escapa à regra e no que em qualquer repetição permanece como não-idêntico, razão para o regresso constante a uma criação emblemática de Heiner Goebbels, intitulada Die Wiederholung / La Reprise / The Repetition (1995). Após a publicação de dois volumes dedicados à investigação das transacções intermediais na arte (Die Stimme und ihre Schrift: die Graphophonie der akustischen Kunst, 1993 e Gedächtniskultur des Hörens: Medientransformation von Beckett über Cage bis Mayröcker, 1997), Petra Meyer vem agora defender que antes de investir na significação, a semiótica deve considerar a materialidade do signo e a sua especificidade como meio. Num tempo em que o signo se despediu da moldura metafísica que tradicionalmente o enquadrava, o signo intermedial é um signo de signos, uma derivação labirintica e transformacional que aqui verdadeiramente surpreende a semiótica tal como a conhecemos.
3 Recorde-se a publicação recente, entre nós, de $A$ obra de arte do futuro tradução José M. Justo, Lisboa, Antigona, 2003 